Senologie 2018; 15(02): $27-27$

DOI: $10.1055 / \mathrm{s}-0038-1651746$

Targeted intraoperative radiotherapy (TARGIT) during breast conserving surgery for early

breast cancer in patient after breast augmentation with implants- a case series

\title{
HC Kolberg
}

Marienhospital Bottrop gGmbH, Klinik für Gynäkologie und Geburtshilfe, Bottrop, Deutschland

V Uhl

EpicCare, Emeryville, California, Vereinigte Staaten von Amerika

S Massarut

Centro di Riferimento Oncologico di Aviano, Aviano, Italien

D Holmes

The Margie Petersen Breast Center, Santa Monica, Vereinigte Staaten von Amerika

\section{Liedtke}

Charité Campus Mitte Universitätsmedizin, Berlin, Deutschland

G Lövey

BORAD, Bottrop, Deutschland

JS Vaidya

University College London, London, Vereinigtes Königreich

\section{Background:}

Targeted intraoperative radiotherapy (TARGIT) has become a standard option during breast conserving surgery for selected cases of early breast cancer. Although a growing number of patients are presenting with implants after breast augmentation, no data have been published yet regarding the safety of TARGIT with implants in situ.

\section{Methods:}

We are reporting a case series of 9 patients, who received TARGIT during breast conserving surgery for early breast cancer, had undergone breast augmentation with implants before and wanted their implants to stay in situ. Patients were informed that no published data existed and decided for this approach on an individual basis. 3 patients received additional EBRT after TARGIT because of presence of EIC or LVI. TARGIT was performed using Intrabeam $\AA-50 \mathrm{kV}-\mathrm{X}$-rays delivering $20 \mathrm{~Gy}$ prescribed at the surface of the tumor bed during the initial lumpectomy procedure.

\section{Results:}

Follow-up varied from 76 months to 9 months. 8 patients presented with invasive breast cancer, 1 patient with DCIS. There were no procedure related complications. No breast cancer-related events or any events in any of the patients occurred to date and none have needed to have change of implant.

\section{Conclusion:}

This series of patients with TARGIT during breast conserving surgery for early breast cancer after breast augmentation with implants in situ revealed no safety concerns. This series of a small number of cases gives some confidence in discussing this option with suitable patients. To expand this series, we are gathering details about other cases from the whole TARGIT group worldwide. 